\title{
Is a single low dose of intrathecal morphine a useful adjunct to patient-controlled analgesia for postoperative pain control following lumbar spine surgery? A preliminary report
}

\author{
David Yen MD FRCSC ${ }^{1}$, Kim Turner MD FRCPC ${ }^{2}$, David Mark MD FRCPC ${ }^{2}$
}

\begin{abstract}
D Yen, K Turner, D Mark. Is a single low dose of intrathecal morphine a useful adjunct to patient-controlled analgesia for postoperative pain control following lumbar spine surgery? A preliminary report. Pain Res Manag 2015;20(3):129-132.
\end{abstract}

BACKGROUND: Several studies addressing intrathecal morphine (ITM) use following spine surgery have been published either involving the pediatric population, using mid- to high-dose ITM, or not in conjunction with morphine patient-controlled analgesia (PCA).

OBJECTIVES: To determine whether low-dose ITM is a useful adjunct to PCA for postoperative pain control following elective lumbar spine surgery in adults.

METHODS: Thirty-two patients were enrolled in a double-blinded randomized controlled trial, and received either ITM or intrathecal placebo. Postoperatively, all patients were given a PCA pump and observed for the first $24 \mathrm{~h}$ in a step-down unit. Measurements of: total PCA morphine consumed in the first $24 \mathrm{~h}$; intensity of pain; pruritus; nausea at $4 \mathrm{~h}, 8 \mathrm{~h}$ and $24 \mathrm{~h}$; time to first ambulation; length of hospital stay; and occurrences of respiratory depression were recorded.

RESULTS: The total PCA use was significantly lower in the ITM group. There were lower average pain scores in the ITM group, which increased to that of the intrathecal placebo group over $24 \mathrm{~h}$; however, this failed to attain statistical significance. There were no differences in nausea, pruritus, time to first ambulation or hospital length stay. There were no cases of respiratory depression in either group.

CONCLUSIONS: ITM may be a useful adjunct to PCA, but did not

Key Words: Intrathecal morphine; Lumbar spine surgery decrease time to ambulation or length of stay.

\section{Une seule faible dose de morphine par voie} intrathécale est-elle un ajout utile à l'analgésie contrôlée par le patient pour contrôler la douleur après une opération de la colonne lombaire?

\section{Un rapport préliminaire}

HISTORIQUE : Plusieurs études portent sur l'utilisation de morphine par voie intrathécale (MIT) après une opération de la colonne vertébrale auprès de la population pédiatrique, à l'aide de doses modérées à élevées de MIT ou auprès de la population adulte conjointement à une analgésie contrôlée par le patient (ACP) au moyen de morphine.

OBJECTIFS : Déterminer si une faible dose de MIT est un ajout utile à l'ACP pour contrôler la douleur postopératoire après une opération non urgente de la colonne lombaire chez des adultes.

MÉTHODOLOGIE : Trente-deux patients ont participé à un essai aléatoire et contrôlé à double insu et ont reçu de la MIT ou un placebo par voie intrathécale. Après l'opération, tous les patients ont reçu une pompe d'ACP et été observés pendant les 24 premières heures dans une unité de soins courants. Les chercheurs ont colligé les mesures totales d'ACP au moyen de morphine consommée pendant les 24 premières heures, l'intensité de la douleur, le prurit, les nausées au bout de quatre, huit et 24 heures, le délai jusqu'à l'ambulation, la durée d'hospitalisation et les occurrences de dépression respiratoire.

RÉSULTATS : L'utilisation totale d'ACP était considérablement plus faible dans le groupe prenant de la MIT. Les scores de douleur moyens étaient moins élevés dans le groupe prenant de la MIT, mais sur 24 heures, ils correspondaient à ceux du groupe prenant un placebo par voie intrathécale. Ce résultat n'avait toutefois pas de signification statistique. Il n'y avait pas de différence sur le plan des nausées, du prurit, du délai jusqu'à l'ambulation ou de la durée d'hospitalisation. Aucun des groupes n'incluait de cas de dépression respiratoire.

CONCLUSIONS : La MIT peut être un ajout utile à l'ACP, mais elle ne réduit pas le délai avant l'ambulation ni la durée d'hospitalisation.

Dreoperative use of narcotics for pain management (1) and soft tissue dissection in posterior spine surgery $(2,3)$ lead to significant postoperative pain. Increased demand for spine surgery, and emphasis on patient-centred care and reduced length of stay in hospital, has led to a search for better methods of postoperative pain management. Intrathecal administration of opioids for acute and severe pain relief in humans was first reported by Wang et al (4) in 1979. Morphine was the first to receive United States Food and Drug Administration approval for epidural and intrathecal use, and remains the most widely investigated and extensively used spinal opioid for postoperative analgesia. There are reports regarding the analgesic efficacy of intrathecal morphine (ITM) (4-7) as well as concerns about its use (8). The reported high incidence of respiratory depression and somnolence (9) led Etches et al (10) to state that until the effect on outcome, morbidity and mortality are known, the value of spinal opioids for the management of postoperative pain is unproven. Others believe that the risk for respiratory depression and somnolence was related to the high opioid doses used, and lowering opioid doses has been advocated $(5,11,12)$. ITM $\leq 0.1 \mathrm{mg}$ has been shown to be an effective, convenient and simple method for managing postoperative pain after Caesarean section $(5,13,14)$ and cholecystectomy $(15)$. Other operations, such as cardiac (16), orthopedic $(6,11,17)$, hysterectomy (18), thoracic (7) or spinal surgeries $(2,19-24)$, have used larger doses of morphine to achieve adequate pain relief. Gwirtz et al (25) reported high patient satisfaction and a low incidence of side effects and complications in $>6000$ patients who underwent major urological, orthopedic, general/vascular, thoracic and nonobstetrical gynecological surgery.

While several studies addressing ITM use following spine surgery have been published, they have involved the pediatric population $(3,22,24,26,27)$, used mid- to high-dose ITM $(19,20,22,23,26,27)$, had no placebo control group (21), used as-needed parenteral narcotics (1) or used piritramide patient-controlled analgesia (PCA) (2) for the control group.

${ }^{1}$ Department of Surgery; ${ }^{2}$ Department of Anesthesiology and Perioperative Medicine, Queen's University, Kingston, Ontario Correspondence: Dr David Yen, Department of Surgery, Queen's University, Kingston, Ontario. Telephone 613-548-2545,

fax 613-548-2518, e-mail yend@kgh.kari.net 
TABLE 1

Demographic characteristics of participants

\begin{tabular}{lccc}
\hline Characteristic & ITM & ITP & $\mathbf{P}^{*}$ \\
\hline Sex, female/male, $\mathrm{n} / \mathrm{n}$ & $7 / 11$ & $3 / 11$ & 0.29 \\
Age, years, mean & 54.6 & 54.8 & 0.96 \\
American Society of & 2.1 & 2.3 & 0.69 \\
$\quad \begin{array}{l}\text { Anesthesiologists } \\
\quad \text { classification, mean }\end{array}$ & & & \\
Fusion, $\mathrm{n}$ & & 3 & 0.46 \\
\hline
\end{tabular}

${ }^{*}$ Calculated using $X^{2}$ tests or two-tailed $\mathrm{t}$ tests as appropriate; ${ }^{\dagger}$ Range $1-3$. ITM Intrathecal morphine; ITP Intrathecal placebo

The primary aim of the present study was to determine whether administration of low-dose ITM is a useful adjunct to PCA for providing postoperative pain control following elective lumbar spine surgery in the adult population. The secondary goals were to determine whether ITM affected hospital length of stay, time to ambulation and occurrences of respiratory depression.

\section{METHODS}

Patients undergoing elective lumbar laminectomy performed by a single surgeon, with or without fusion, and with or without instrumentation, were considered for entry into the study. Inclusion criteria were signed informed consent and age $>16$ years and $<70$ years. Exclusion criteria were pregnancy, allergy/intolerance to any of the study medications, chronic morphine use, history of sleep apnea and inability to use PCA.

Intraoperatively, patients all received intravenous fentanyl $1 \mu \mathrm{g} / \mathrm{kg}$ to $3 \mu \mathrm{g} / \mathrm{kg}$, intravenous sodium thiopental $3 \mathrm{mg} / \mathrm{kg}$ to $5 \mathrm{mg} / \mathrm{kg}$ and neuromuscular relaxant, at the discretion of the anesthesiologist; per rectum acetaminophen $1300 \mathrm{mg}$ postinduction; maintenance of anesthesia with $60 \%$ to $70 \%$ nitrous oxide and isoflurane at $0.02 \%$ to $1.0 \%$ end-tidal concentration; and additional intravenous fentanyl (up to $8 \mu \mathrm{g} / \mathrm{kg}$ ) at the discretion of the anesthesiologist.

Research ethics board approval was obtained. Thirty-two consecutive consenting adult patients with American Society of Anesthesiologists health status classifications I, II or III admitted for elective lumbar spinal decompression with or without spinal fusion over a 46-month period were included. Intraoperatively, the patients were randomly assigned to either receive the ITM or intrathecal placebo (ITP). At the conclusion of the operative procedure and before closure, the surgeon administered an identical solution prepared by the pharmacy of either $3.5 \mu \mathrm{g} / \mathrm{kg}$ to a maximum of $350 \mu \mathrm{g}$ of preservative-free morphine (ITM group) or a placebo consisting of an equivalent volume of preservative-free isotonic saline (ITP group) into the intrathecal space under direct visualization using a 30 -gauge needle with the bevel perpendicular to the dura. Less than $5 \mu \mathrm{g} / \mathrm{kg}$ is considered to be a low dose $(3,27)$; thus, $3.5 \mu \mathrm{g} / \mathrm{kg}$ ITM was used with morphine PCA, with the hypothesis that the former would limit the risk of respiratory depression and the latter would provide the option for supplemental morphine and optimize pain control for patients undergoing lumbar spine surgery. On wound closure, all patients received $10 \mathrm{~mL}$ of $0.25 \%$ bupivicaine with 1:200,000 epinephrine in the subcutaneous tissue surrounding the skin incision, intravenous ondansetron $4 \mathrm{mg}$ before emergence and reversal of neuromuscular blockade at the discretion of the attending anesthesiologist. Both the surgeon and the anesthesiologist were blinded to the study group allocation.

Postoperatively, all patients were given a PCA pump with initial programming consisting of morphine $2.5 \mathrm{mg} / \mathrm{mL}$, bolus of $0.02 \mathrm{mg} / \mathrm{kg}$ (maximum $2.0 \mathrm{mg}$ ) and lockout of $5 \mathrm{~min}$, with no background infusion. They all received per rectum acetaminophen 1300 mg every $8 \mathrm{~h}$ while nil per os or oral acetaminophen $650 \mathrm{mg}$ every $4 \mathrm{~h}$ while awake, intravenous/ intramuscular dimenhydrinate $25 \mathrm{mg}$ every $4 \mathrm{~h}$ as needed. Subsequent management of the PCA pump was at the discretion of the acute pain
TABLE 2

Independent-samples tests for group statistics

\begin{tabular}{|c|c|c|c|c|}
\hline & \multirow[b]{2}{*}{$\begin{array}{c}\text { Time } \\
\text { postoperatively, } \mathbf{h}\end{array}$} & \multicolumn{2}{|c|}{ Group } & \multirow[b]{2}{*}{$\mathbf{P}^{*}$} \\
\hline & & $\begin{array}{l}\text { Intrathecal } \\
\text { morphine }\end{array}$ & $\begin{array}{l}\text { Intrathecal } \\
\text { placebo }\end{array}$ & \\
\hline $\begin{array}{l}\text { Total } 24 \mathrm{~h} \text { patient- } \\
\text { controlled } \\
\text { analgesia, mg }\end{array}$ & & 32.7 & 59.4 & 0.04 \\
\hline \multirow[t]{3}{*}{ Nausea intensity ${ }^{\dagger}$} & 4 & 1.4 & 1.1 & 0.14 \\
\hline & 8 & 1.3 & 1.1 & 0.23 \\
\hline & 24 & 1.4 & 1.2 & 0.56 \\
\hline \multirow[t]{3}{*}{ Pruritus intensity ${ }^{\dagger}$} & 4 & 1.5 & 1.1 & 0.15 \\
\hline & 8 & 1.7 & 1.4 & 0.32 \\
\hline & 24 & 1.5 & 1.5 & 0.91 \\
\hline $\begin{array}{l}\text { Time to ambulation, } \\
\text { min }\end{array}$ & & 1853 & 1705 & 0.81 \\
\hline $\begin{array}{l}\text { Hospital length of } \\
\text { stay, days }\end{array}$ & & 4.7 & 3.6 & 0.14 \\
\hline
\end{tabular}

$\overline{D a t a}$ presented as mean unless otherwise indicated. *According to two-tailed

t test; ${ }^{\dagger}$ On a scale of 1 to 4

management anesthesiologist, who was blinded to patient allocation, with the proviso that background infusions were not to be used.

All patients were monitored for the first $18 \mathrm{~h}$ to $24 \mathrm{~h}$ postoperatively in a step-down unit with continuous oxygen saturation monitoring. The postoperative outcome measures that were evaluated and recorded were: pain intensity, graded by the patient from 1 to 10 ; total PCA morphine used in the first $24 \mathrm{~h}$ postoperatively, measured in milligrams; time to first ambulation, measured in minutes; length of hospital stay, measured in days; nausea intensity, graded by the patient from 1 to 4; pruritis intensity, graded by the patient from 1 to 4 ; and episodes of respiratory depression (rate $<9$ breaths/min).

Statistical analysis was performed using a series of independentsamples $t$ tests to compare the two groups with regard to all of the various outcomes. With this sample size, $\mathrm{P}<0.05$ was considered to be statistically significant. While there are three temporal measures for each patient, repeated-measures ANOVA was not performed because within-person change over time was not of interest; rather, the between-group differences at each point in time were the focus of the analysis. No a priori adjustments were made for multiple comparisons; rather, all $\mathrm{P}$ values and sample sizes are presented to enable the reader to interpret the data in the context of the comparisons.

\section{RESULTS}

The ITM group included 18 patients and the ITP group included 14 patients. The groups were not significantly different according to patient age, sex, American Society of Anesthesiologists classification and whether a fusion was performed in addition to the lumbar decompression (Table 1).

The average total PCA use over the first postoperative $24 \mathrm{~h}$ was significantly less in the ITM group (32.7 $\mathrm{mg}$ versus $59.4 \mathrm{mg} ; \mathrm{P}=0.04$ ) (Table 2). There were lower average pain scores in the ITM group at $4 \mathrm{~h}(\mathrm{P}=0.11)$ and at $8 \mathrm{~h}(\mathrm{P}=0.07)$ postoperatively; however; this did not attain statistical significance. There was no difference at $24 \mathrm{~h}$ postoperatively $(\mathrm{P}=0.90)$ (Figure 1$)$. There were no episodes of respiratory depression experienced by patients in either group.

There was no difference between the groups with regard to nausea at $4 \mathrm{~h}(\mathrm{P}=0.14), 8 \mathrm{~h}(\mathrm{P}=0.23)$ and $24 \mathrm{~h}(\mathrm{P}=0.56)$ postoperatively; pruritus at $4 \mathrm{~h}(\mathrm{P}=0.15), 8 \mathrm{~h}(\mathrm{P}=0.32)$ and $24 \mathrm{~h}(\mathrm{P}=0.91)$ postoperatively; time to first ambulation $(\mathrm{P}=0.81)$; and hospital length of stay $(\mathrm{P}=0.14)$ (Table 2).

Sample size calculations were derived on the basis of the cumulative patient-controlled morphine delivered in the first $24 \mathrm{~h}$, as reported by France et al (19). SDs were not provided but are estimated on the basis of the magnitude in the current study. Using a mean $( \pm$ SD) of 


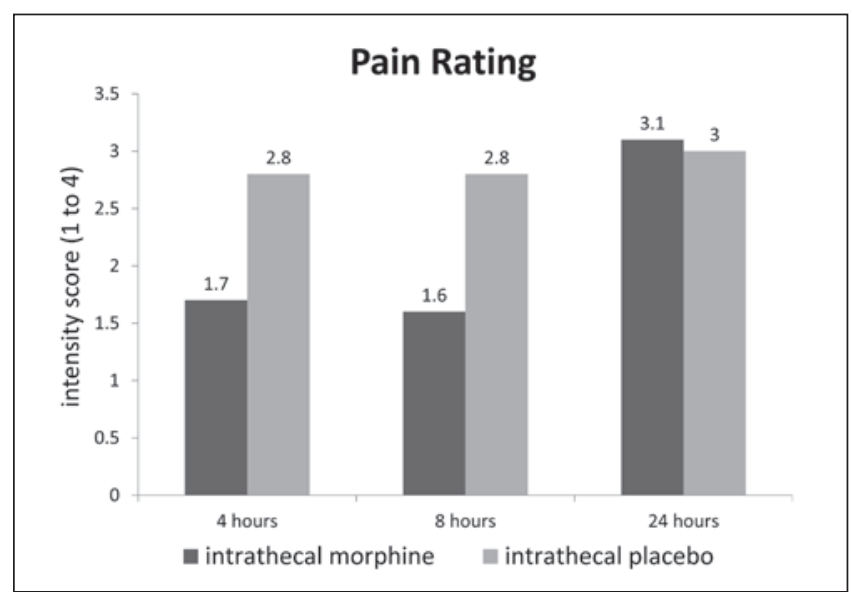

Figure 1) Pain scores in the intrathecal morphine versus intrathecal placebo groups

$7 \pm 5.2$ and a mean of $25.5 \pm 19.1$, an alpha of 0.05 and a two-tailed test, the study would have a power of $80 \%$ with only 10 patients in each group; this suggests that the current number of 18 and 14 patients would provide adequate power to detect difference in morphine delivery.

The study by France et al (19) noted few differences in the complication rates. Itchiness was noted in eight experimental and two control patients; need for nalaxone due to a respiratory rate $<8$ breaths/min was demonstrated in three experimental patients and none of the control patients. Neither attained statistical significance. Using an alpha of 0.05 and a power of $80 \%, 130$ patients per group would be required for this to attain statistical significance, suggesting that the current study, as well as the study by France et al (19), were both underpowered to detect these complications. However, sample size calculations are not as relevant in the case of relatively rare events and, given that the use of morphine was the primary outcome, the present study had sufficient power for this outcome.

\section{DISCUSSION}

Similar to France et al (19), we found that the average total PCA use over the first postoperative $24 \mathrm{~h}$ was significantly lower in the ITM group, although we used a low dose rather than the mid-range dose that France et al (19) used. Therefore, low-dose ITM is an effective early adjunct to PCA in decreasing the amount of self-administered systemic morphine in patients undergoing lumbar spine surgery.

The average pain scores in the ITM group were lower for the first $8 \mathrm{~h}$ postoperatively; however, this did not attain statistical significance.

There were no episodes of respiratory depression experienced by patients in the ITM with PCA group. Therefore, although the present study had a small sample size, our data support clinicians who believe that respiratory depression is dose dependent and advocate using low-dose ITM.

There were no differences in measured nausea and pruritus between the ITM and ITP groups. Interestingly, therefore, decreasing the amount of systemic morphine using ITM did not result in less nausea or pruritis in our patients.

We found no difference in time to ambulation or length of stay with the use of ITM. We believe this may be because time to ambulation and length of stay after spine surgery is determined not by postoperative pain but by multiple factors such as preoperative deconditioning, postoperative fatigability and the patients' home support system. Therefore, in the present study, ITM was not a useful adjunct for decreasing hospital resource utilization in lumbar spine surgery.

The strength of our study was in its design methodology. The weakness is the small sample size, which may have reduced our ability to find a statistically significant difference in pain scores in favour of ITM.

\section{CONCLUSION}

ITM was an effective adjunct to PCA for decreasing the amount of self-administered systemic morphine required by patients undergoing lumbar spine surgery. Further studies, including larger sample sizes, are needed to show that a low dose provides superior early postoperative pain relief compared with PCA alone, with less respiratory depression than mid-range doses of ITM.

ACKNOWLEDGEMENT: The authors thank Wilma Hopman MA for the statistical analysis of the data.

FUNDING: This study was supported by a grant from the Kingston General Hospital Foundation (Kingston, Ontario).

\section{REFERENCES}

1. Ross DA, Drasner K, Weinstein PR, Flaherty JF, Barbaro NM. Use of intrathecally administered morphine in the treatment of postoperative pain after lumbar spinal surgery: A prospective, double-blind, placebo-controlled study. Neurosurgery 1991;28:700-4.

2. Ziegeler S, Fritsch E, Bauer C, et al. Therapeutic effect of intrathecal morphine after posterior lumbar interbody fusion surgery: A prospective, double-blind, randomized study. Spine 2008;33:2379-86.

3. Gall O, Aublneau J-V, Berniére J, Desjeux L, Murat I. Analgesic effect of low-dose intrathecal morphine after spinal fusion in children. Anesthesiology 2001;94:447-52.

4. Wang JK, Nauss LA, Thomus JE. Pain relief by intrathecally applied morphine in man. Anaesthesiology 1979;50:149-51.

5. Abbound TK, Dror A, Mosaad P, et al. Mini-dose intrathecal morphine for the relief of post-cesarean section pain: Safety, efficacy, and ventilatory response to carbon dioxide. Anesth Analg 1988;67:137-43.

6. Kalso E. Effects of intrathecal morphine injected with bupivacaine on pain after orthopedic surgery. Br J Anaesthiol 1983;55:415-22.

7. Nordberg G, Hedner T, Mellstrand T, Dahlstrom B. Pharmacokinetic aspects of intrathecal morphine analgesia. Anaesthesiology 1984;60:448-54.

8. Meylan N, Elia N, Lysakowski C, Tramèr MR. Benefit and risk of intrathecal morphine without local anaesthetic in patients undergoing major surgery: Meta-analysis of randomized trials. Br J Anaesth 2009;102:156-67.

9. Gustafsson LL, Schildt B, Jacobsen K. Adverse effects of extramural and intramural opioids: Report of a nationwide survey in Sweden. Br J Anaesth 1982;54:479-86.

10. Etches RC, Sandler AN, Daley MD. Respiratory depression and spinal opiods. Can J Anaesth 1989;36:165-85.

11. Jacobson L, Chabal C, Brody MC. A dose-response study of intrathecal morphine: Efficacy, duration, optimal dose, and side effects. Anesth Analg 1988;67:1082-8.

12. Bailey PL, Rhondeau S, Schafer PG, et al. Dose response pharmacology of intrathecally morphine in human volunteers. Anaesthesiology 1993;79:49-59.

13. Swart M, Sewell J, Thomas D. Intrathecally morphine for C-Section: An assessment of pain relief, satisfaction and side effects. Anaesthesia 1997;52:373-7.

14. Palmer CM, Emerson S, Volgoropolous D, Alves D. Dose response relationship of intrahecal morphine for postcesarean analgesia. Anaesthesiology 1999;90:437-44.

15. Yamaguchi $H$, Watanabe $S$, Motokawa K, Ishizawa Y. Intrathecal morphine dose-response data for pain relief after cholecystectomy. Anesth Analg 1990;70:168-71.

16. Vanstrum GS, Bjornson KM, Ilko R. Postoperative effects of intrathecal morphine in CABG surgery. Anesth Analg 1988;67:261-7.

17. Cole PJ, Craske DA, Wheatley RG. Efficacy and respiratory effects of low dose spinal morphine for post-operative analgesia following knee arthoplasty. Br J Anaesth 2000;85:233-7. 
18. Sarma VJ, Bostrom UV. Intrathecally morphine for the relief of post hysterectomy pain - a double blind dose response study. Acta Anaesthesiol Scand 1993;37:223-7.

19. France JC, Jorgenson SS, Lowe TG, Dwyer AP. The use of intrathecal morphine for analgesia after poster lateral lumbar fusion.

A prospective, double-blind, randomized study. Spine 1997;22:2272-7.

20. O'Neil P, Knickenberg C, Bogahalanda S, Booth AE. Use of intrathecal morphine for postoperative pain relief following lumbar spinal surgery. J Neurosurgery 1985;63:413-6.

21. Boezaart AP, Eksteen JA, Spuy, GV, Rossouw P, Knipe M. Double-blind evaluation of optimal dosage for analgesia after major lumbar spinal surgery. Spine 1999;24;11:1131-7.

22. Tripi PA, Poe-Kochert C, Potzman J, Son-Hing JP, Thompson GH. Intrathecal morphine for postoperative analgesia in patients with idiopathic scoliosis undergoing posterior spinal fusion.

Spine 2008;33:2248-51.

23. Urban MK, Jules-Elysee K, Urquhart B, Cammisa FP, Boachie-Adjei O. Reduction in postoperative pain after spinal fusion with

instrumentation using intrathecal morphine. Spine 2002;27:535-7.
24. Blackman RG, Reynolds, J, Shively J. Intrathecal morphine: Dosage and efficacy in younger patients for control of postoperative pain following spinal fusion. Orthopedics 1991;14:555-62.

25. Gwirtz KH, Young JV, Byers RS, et al. The safety and efficacy of intrathecal opioid analgesia for acute post-operative pain. Seven years' difference with 5,969 surgical patients at Indiana University Hospital. Anesth Analg 1999;88:599-604.

26. Poe-Kochert C, Tripi PA, Potzman J, Son-Hing JP, Thompson GH. Continuous intravenous morphine infusion for postoperative analgesia following posterior spinal fusion for idiopathic scoliosis. Spine 2010;35:754-7.

27. Milbrandt TA, Singhal M, Minter C, et al. A comparison of three methods of pain control for posterior spinal fusions in adolescent idiopathic scoliosis. Spine 2009;34:1499-502. 


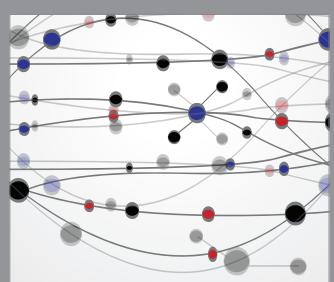

The Scientific World Journal
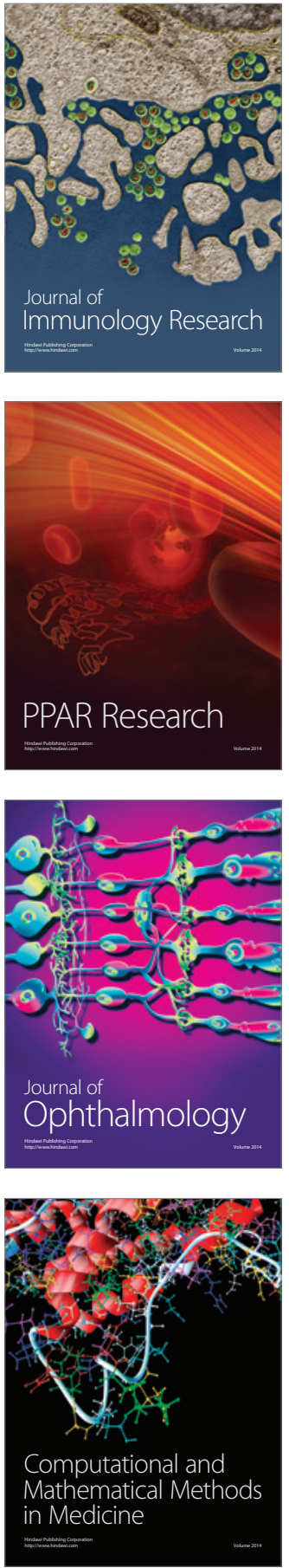

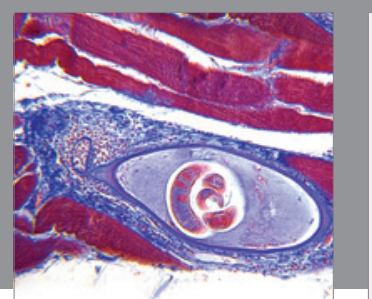

Gastroenterology Research and Practice

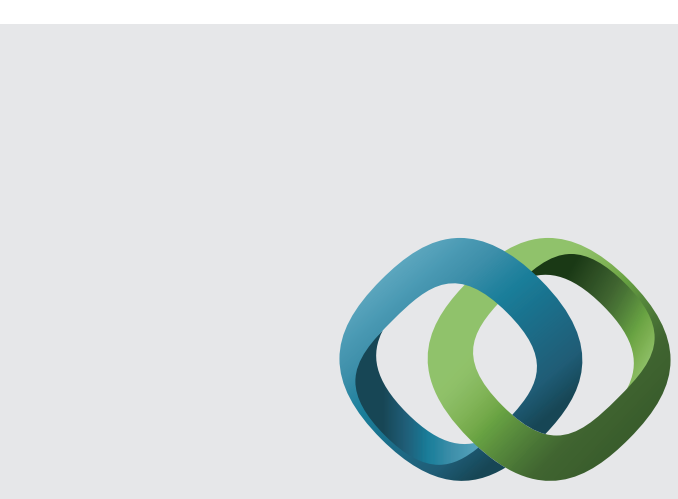

\section{Hindawi}

Submit your manuscripts at

http://www.hindawi.com
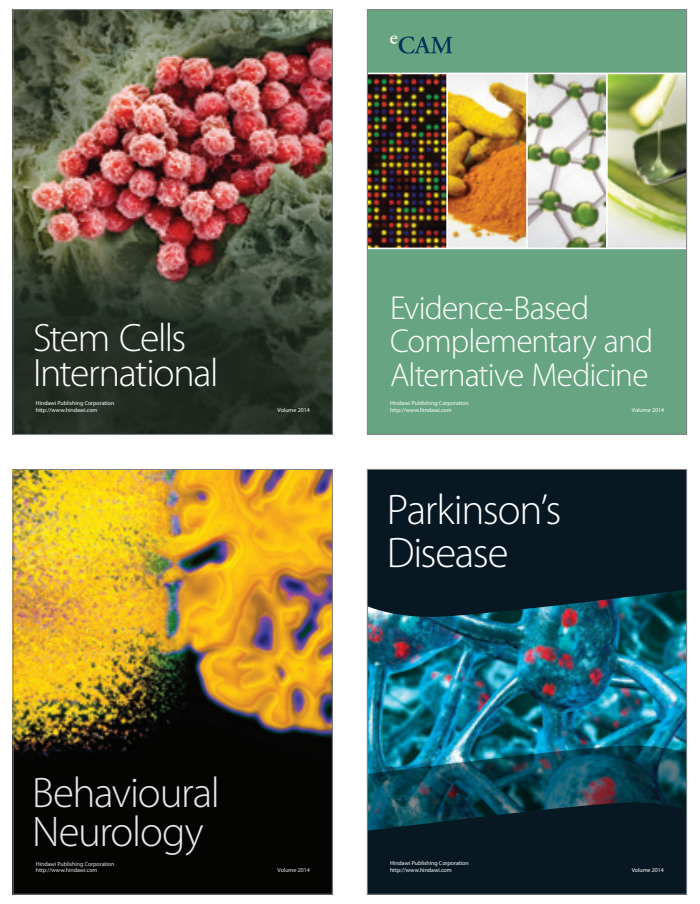
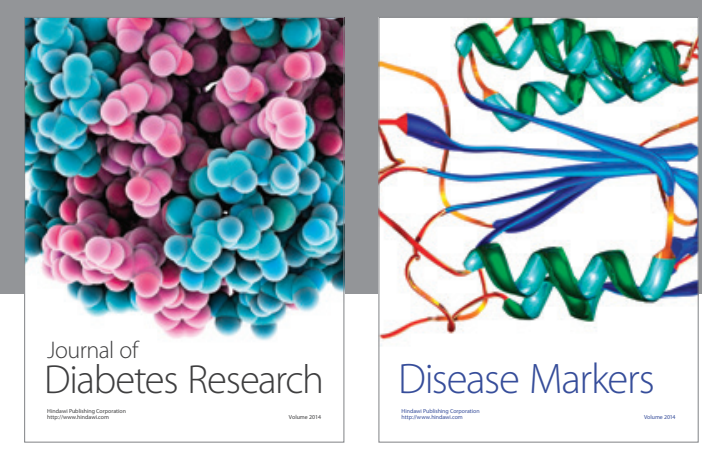

Disease Markers
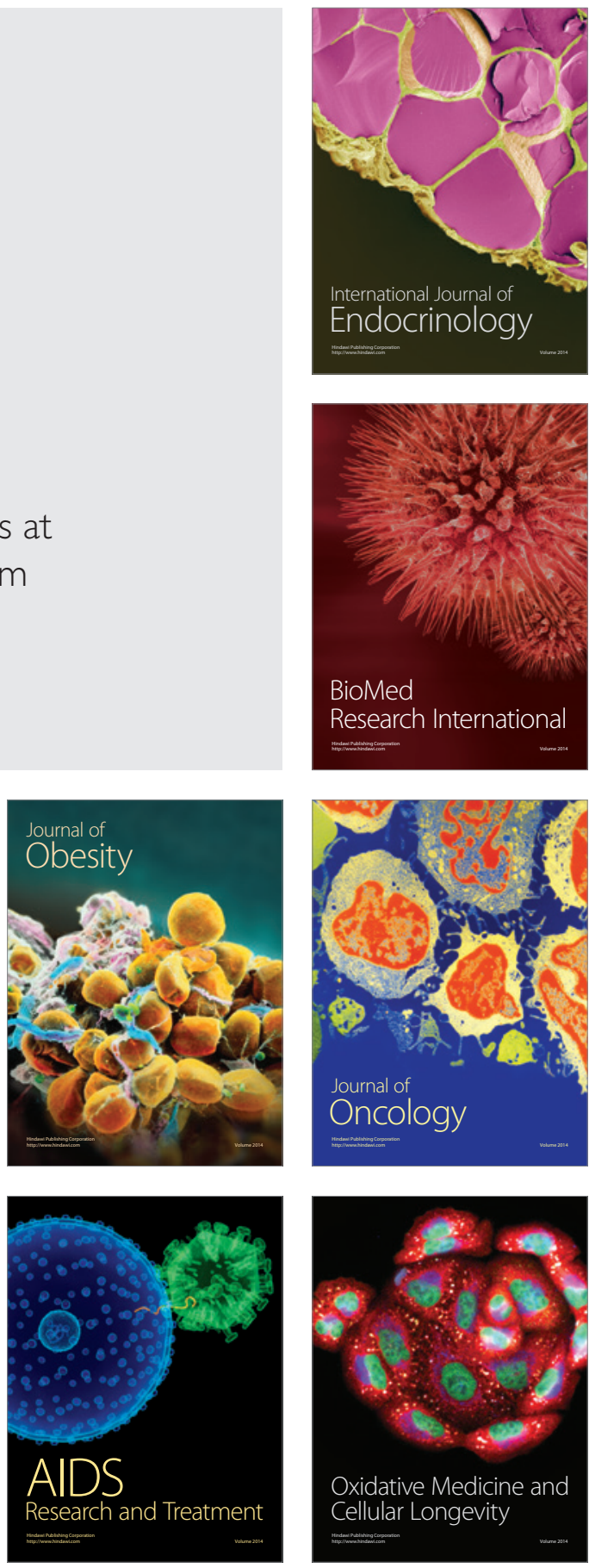